\title{
Psychometric Properties of the Portuguese Version of the Posttraumatic Growth Inventory Short Form Among Divorced Adults
}

\author{
Diogo Lamela ${ }^{1}$, Bárbara Figueiredo ${ }^{1}$, Alice Bastos², and Helena Martins ${ }^{3}$ \\ ${ }^{1}$ University of Minho, Braga, Portugal, ${ }^{2}$ Polytechnic Institute of Viana do Castelo, Portugal, \\ ${ }^{3}$ Polytechnic Institute of Porto, Porto, Portugal
}

\begin{abstract}
The aim of this study was to develop and validate a Portuguese version of the Short Form of the Posttraumatic Growth Inventory (PTGI-SF). Using an online convenience sample of Portuguese divorced adults $(N=482)$, we confirmed the oblique five-factor structure of the PTGI-SF by confirmatory factor analysis. The results demonstrated the measurement invariance across divorce initiator status groups. Total score and factors of PTGI-SF showed good internal consistency, with the exception of the New Possibilities factor, which revealed an acceptable reliability. The Portuguese PTGI-SF showed a satisfactory convergent validity. In terms of discriminant validity, posttraumatic growth assessed by the Portuguese PTGI-SF was a distinct factor from posttraumatic psychological adjustment. These preliminary findings suggest the cultural adaptation and also psychometric properties of the present Portuguese PTGI-SF to measure posttraumatic growth after personal crisis.
\end{abstract}

Keywords: posttraumatic growth, Posttraumatic Growth Inventory, stress, assessment, divorce, personal growth

Past empirical research showed that major life events or traumatic experiences may produce severe psychological consequences and chronic maladjustment symptoms. Similarly, some authors have argued that major life events can also trigger positive outcomes. However, the definition of traumatic event and consequently the extension and interpretability of personal growth outcomes in the aftermath of a stressor are not consensual in the scientific community. While some theoretical frameworks associate only a trauma experience to specific rare life-threatening events (Breslau \& Kessler, 2001), other perspectives underline the subjective perception of the amount of stress experienced as the main criterion for defining an event as traumatic or highly stressful (McCann \& Pearlman, 1990). A third group of scholars proposes that a trauma experience is not associated with a particular type of events, but is rather defined by the presence of a core of psychopathological symptoms (Brewin, Lanius, Novac, Schnyder, \& Galea, 2009). In an integrative view, these frameworks postulate that, in order to be considered as highly stressful or a traumatic experience, an event may depend on frequency, duration, sense of predictability, strength of impact, and controllability of the stressor as well as the subjective assessment of personal ability to cope with such events and how these events interfere in standards of living, personal values, and personal meaning-making processes (Brewin et al., 2009; Calhoun \& Tedeschi, 2006).

In this sense, no clear boundary can be established between traumatic and nontraumatic experiences (Weathers $\&$ Keane, 2007). For example, Calhoun and Tedeschi (2006) assumed this diffuse conceptual boundary by proposing a broader formulation of trauma wherein "the terms of trauma, crisis, major stressor, and related terms [are] essentially synonymous expressions to describe circumstances that significantly challenge or invalidate important components of the individual's assumptive world" (Calhoun \& Tedeschi, 2006, p. 3). Prior research supported this idea by substantiating that stressful events such as divorce, family conflict, chronic illness, problems with work, or expected death of a loved one can produce at least as many posttraumatic symptomatology as rare traumatic events (e.g., a disaster, sexual abuse victimization, sudden death of loved one) (Mol et al., 2005; Robinson \& Larson, 2010).

Despite these conceptual controversies in defining a traumatic, stressful, or common significant life event, the scientific literature systematically shows that life events can potentially trigger positive outcomes as well (Helgeson, Reynolds, \& Tomich, 2006). The study of predictors, moderate 
and mediator mechanisms and outcomes of personal growth after stressful events, has systematically increased over the last two decades. Among the numerous scales developed to measure stress-related growth, the one most frequently used in international context is the Posttraumatic Growth Inventory (PTGI; Tedeschi \& Calhoun, 1996). Furthermore, the PTGI is used to measure personal growth following a broad number of life events (ranging from war experience to transition to parenthood), and its construct validity has also received strong empirical evidence (Powell, Rosner, Butollo, Tedeschi, \& Calhoun, 2003; Taku, Cann, Calhoun, \& Tedeschi, 2008; Taubman-Ben-Ari, Ben Shlomo, \& Findler, in press). More recently, a short version of PTGI was developed by Cann et al. (2010), and initial psychometric studies showed that PTGI-SF is a promising measure in terms of construct validity and its easiness of administration in samples that experienced a wide range of life events (Cann et al., 2010; Kaler, Erbes, Tedeschi, Arbisi, \& Polusny, 2011). Based on these recent research results, our study tests the psychometric properties of the Portuguese version of the PTGI-SF.

\section{Posttraumatic Growth}

During the last two decades, a large and growing body of research has revealed that some individuals who experienced highly stressful events also showed positive outcomes related to those experiences. In the psychology literature, positive psychological changes triggered by facing challenging adverse life events are referred to as posttraumatic growth (PTG; Tedeschi \& Calhoun, 2004). Equally termed as stressrelated growth, perceived benefits, or adversarial growth (Linley \& Joseph, 2004), PTG describes the acquisition of more complex coping skills, the development of new perspectives about the self and the world, the improvement of interpersonal relationships, a greater sense of appreciation of life, and changes in life goals as contingent results of the struggle with the aftermath of the stressor (Frazier \& Kaler, 2006; Tedeschi, Calhoun, \& Cann, 2007). PTG outcomes have been reported in individuals who have experienced a broad range of stressful events, such as cancer (Brunet, McDonough, Hadd, Crocker, \& Sabiston, 2010), bereavement (Engelkemeyer \& Marwit, 2008), war experience (Kaler et al., 2011), chronic illness (Tran, Wiebe, Fortenberry, Butler, \& Berg, 2011), dissolution of romantic relationships (Ty Tashiro \& Frazier, 2003), and coming out to others as a sexual minority (Vaughan \& Waehler, 2010).

Prior research established that personal growth happens not only as a result of traumatic experiences, as defined by DSM-IV-TR (American Psychiatric Association, 2000), in which a traumatic event occurs exclusively when the life of the individual was threatened or the individual witnessed an event that may jeopardize the life or the physical integrity of others. Rather, some studies consistently demonstrated that stressors that did not correspond to the DSMIV-TR criteria may be considered a traumatic experience (e.g., divorce and unemployment) that may also produce acute stress maladjustment symptoms and posttraumatic stress responses similar to life-threatening events - and generate stress-related growth as well (Dohrenwend, 2010; Mol et al., 2005).

\section{Eudaimonic Nature of Posttraumatic Growth}

Previous research revealed that PTG and posttraumatic psychological adjustment are distinct but related dimensions of positive human functioning after a stressful event. According to Joseph and Linley (2005), posttraumatic psychological (mal)adjustment and PTG should not be conceptualized as opposite poles of a continual construct. Rather, these dimensions are both aspects of optimal well-being after a stressful event, though they describe different outcomes and are caused by distinct psychological processes (Joseph \& Linley, 2005; Tedeschi et al., 2007). In other words, while PTG reflects an eudaimonic view of positive human functioning, posttraumatic psychological adjustment is related to a hedonic pathway of positive human functioning (Tedeschi et al., 2007). In this sense, as described above, PTG refers to the development of a profounder and wider view of the self, the others and the world, the development of a more complex emotional and cognitive regulation system, as well as the development of a more complex meaning, purpose, and psychological maturity, which results in psychological well-being (Calhoun \& Tedeschi, 2006; Joseph \& Linley, 2005; Staudinger \& Kunzmann, 2005). By contrast, posttraumatic psychological adjustment refers to the level of proficiency an individual has in coping with challenging constraints raised by the stressor as well as the individual's ability to balance affective states and achieve levels of satisfaction with life and happiness resulting in subjective well-being (Joseph \& Linley, 2005).

These differences between indicators of psychological adjustment (also termed hedonic well-being or subjective wellbeing; Ryan \& Deci, 2001) and psychological well-being (or eudaimonic well-being; Ryan \& Deci, 2001) are theoretically and empirically well established in developmental and personality psychology literatures (Keyes, Shmotkin, \& Ryff, 2002; Ryan \& Deci, 2001). Conceptually, the constructs of posttraumatic growth and psychological well-being are derived from the eudaimonic perspective of the study of wellbeing (Joseph \& Linley, 2005). Durkin and Joseph (2009), for example, in a sample of college students who had experienced a stressful event, found empirical evidence of this theoretical tenet by demonstrating that posttraumatic growth was more associated with psychological well-being rather than with psychological adjustment.

\section{Assessment of Posttraumatic Growth}

Several self-report instruments were developed to measure potential psychological growth after adversity. Despite this 
diversity, the Posttraumatic Growth Inventory (PTGI; Tedeschi \& Calhoun, 1996) has become the most used instrument in international research and has been administered to an extensive variety of populations (Calhoun \& Tedeschi, 2006). The five subscales of the PTGI capture the broad categories that theoretically are considered to be the basis of stress-related growth: changes in the perception of the self, changes in interpersonal relationships, and changes in the philosophy of life (Tedeschi \& Calhoun, 1996). Additionally, some authors have also found evidence of the PTGI construct validity to measure personal growth outcomes following non-life-threatening stressful or common significant life events besides traumatic and highly stressful experiences (Taubman-Ben-Ari et al., in press; Weinrib, Rothrock, Johnsen, \& Lutgendorf, 2006).

Globally, satisfactory psychometric properties have been found in the original and international versions of 21item PTGI. Recently, using data from 926 participants, Taku et al. (2008) compared five different possible models of the latent factor structure of the inventory. In this study, the authors confirmed the oblique five-factor structure of PTGI, after testing whether it was composed of three factors (the broad dimensions of posttraumatic growth described above), five factors (the five subscales of the original version of the PTGI) or a single and general factor (as a consequence of the moderate to high intercorrelations among the five factors of the original PTGI version found in previous studies).

More recently, Cann et al. (2010) developed a short version of PTGI. Two main reasons motivated the development of PTGI-SF. First, under extreme unhealthy conditions, even the PTGI can demand an excessive physical effort from participants. Second, the administration of several measures in some research designs and the limited time to data collection can preclude the use of the PTGI-21 items. Prior results reported by Cann et al. (2010) using a total sample of 1,351 adults from 16 previous studies suggested that PTGI-SF is a valid measure for analyzing interindividual differences in psychological growth after highly stressful events. Confirmatory factor analyses of PTGI-SF identified an oblique five-factor structure similar to PTGI and internal consistency values comparable to PTGI-21 items (Cann et al., 2010). In this study, the authors found that PTGI-SF reproduced similar associations between posttraumatic growth measured using PTGI-21 items and variables of interest in samples of survivors of intimate partner violence, bereaved parents, and patients diagnosed with acute leukemia. Kaler and colleagues (2011) replicated the psychometric properties of the PTGI-SF reported by Cann et al. (2010) using a sample of 327 veterans from the Iraq war and demonstrated that PTGI-SF showed satisfactory reliability and supportive values of concurrent validity. Authors also found that an oblique five-factor solution received stronger support for fitting the data, when compared with a one-factor model and with a second-order factor model (Kaler et al., 2011).

\section{The Present Study}

Divorce is considered one of the most stressful events in adulthood (Holmes \& Rahe, 1967; Mol et al., 2005). Adults in the aftermath of divorce report similar depression symptoms, psychological stress, cortisol levels and posttraumatic stress symptoms to those reported by individuals who have experienced life-threatening episodes and other stressful life events (Middeldorp, Cath, Beem, Willemsen, \& Boomsma, 2008; Miller, Chen, \& Zhou, 2007; Mol et al., 2005). Marital dissolution requires a demanding adaptation to significant changes that may synchronically occur in a variety of domains of divorced adults' life (Lamela, Figueiredo, \& Bastos, 2010). Previous studies demonstrated that the loss of the attachment figure, economic decline, the perceived lack of formal and informal social support, and conflicts with the ex-spouse may operate as precipitant events that explain the level of stressfulness of the divorce experience (Amato, 2000). For adults who have children, the maintenance of a coparenting relationship with the exspouse as well as the sole parenting responsibility or the loss of custody of children may intensify the stress experience (Amato, 2000).

Nevertheless, the magnitude of the adverse outcomes produced by divorce can be buffered or exacerbated by some moderator variables, such as divorce initiator status, career status, and existence of a new intimate relationship (Sakraida, 2005; Wang \& Amato, 2000). More concretely, divorce initiator status is highlighted as one of the most robust moderators of the enhancement of quality of life after the marital dissolution (Wallerstein, 1986). Past research with individuals who had divorced, separated, or dissolved a nonmarital relationship consistently revealed that noninitiators of the relationship dissolution reported more psychological distress, more psychosomatic symptoms, and they perceived the dissolution as more stressful (Davis, Shaver, \& Vernon, 2003; Sakraida, 2005; Wang \& Amato, 2000). Noninitiators reported more often feelings of shock with the end of the relationship, lower levels of emotional recovery, as well as a worse sense of event controllability and more emotional attachment to the ex-partner (Davis et al., 2003; Frazier \& Cook, 1993). These negative outcomes seemed to be similar between noninitiators and individuals who mutually initiated the intimate relationship dissolution (Davis et al., 2003).

Furthermore, some authors also argued that divorce may trigger maturation and psychological growth (Tashiro, Frazier, \& Berman, 2006). Previous research showed that adults who experienced divorce reported psychological growth when measured by the PTGI (Krumrei, Mahoney, \& Pargament, 2009). More specifically, divorced adults exhibited an increased sense of autonomy and competence, more developed coping skills, more life reflection skills, more self-confidence, a sense of coherence and optimism, and new life perspectives in consequence of marital dissolution (King \& Raspin, 2004; Kulik \& Heine-Cohen, 2011; Sakraida, 2005; Thomas \& Ryan, 2008). 
Considering this past research, the current study aimed to develop and validate a Portuguese version of the PTGISF using a sample of divorced adults. To reach this goal, we first tested the factor structure of the Portuguese PTGI$\mathrm{SF}$ in order to confirm the oblique five-factor model found in previous studies (Cann et al., 2010; Kaler et al., 2011). However, a substantial interpersonal variability among divorced adults in the stressful impact of divorce experience and in the magnitude of PTG may occur when some moderator variables are considered. Therefore, to overcome psychometric concerns about the PTGI-SF construct validity invariance across different groups, the measurement invariance/equivalence of the final factor solution of the Portuguese PTGI-SF was examined. The divorce initiator status variable was used to test factorial invariance because, among the variables included in this study, this is the best at distinguishing between more likely stressed individuals from less likely stressed individuals. As stated above, if divorce initiator status moderates extensively the amount of stress or trauma experienced in consequence of a marital dissolution (Wallerstein, 1986) it may also moderate the stress-related growth experienced by divorced adults, in which the more likely stressed individuals have more probability of showing more PTG as well (Tedeschi \& Calhoun, 1996). No other variable such as gender or age was considered to test factorial invariance since no theoretical differences in PTGI scores are expected in those variables.

Finally, the internal consistency as well as the convergent and divergent validity were also examined. To the best of our knowledge, with respect to convergent validity there is no another psychometric valid instrument adapted to the Portuguese population that accurately measures PTG. For this reason, we used a measure that closely assesses an associated construct, namely, growth motivation. Growth motivation for psychological well-being refers to the personal motivational effort for self-improvement and the achievement of a profounder knowledge about the self and the world. Previous narrative studies additionally showed that individuals with growth motives of self-improvement and self-exploration exhibited higher psychological wellbeing (Bauer, McAdams, \& Sakaeda, 2005). Thus, considering that posttraumatic growth is defined by the self-perception of changes in the self, in interpersonal relationships, and in the philosophy of life caused by the struggle with a highly challenging event, it is plausible to hypothesize that these two constructs share conceptual similarities. However, we predicted that PTGI-SF and growth motivation assessed by the Growth Motivation Index (Bauer et al., 2011) would only be moderately correlated since the construct of PTG assessed by the PTGI-SF captures other dimensions (e.g., spiritual change) not considered by motivation growth.

Concerning discriminant validity, PTGI-SF was expected to measure PTG as a distinctive construct from psychological adjustment after divorce (Joseph \& Linley, 2005). Previous studies about the relationship between posttraumatic growth and posttraumatic adjustment demonstrated two main findings. First, there is no systematical and causal positive relationship between these two constructs (e.g., Powell et al., 2003). Second, PTG and posttraumatic psychological distress can co-exist (Tedeschi et al., 2007; Zoellner \& Maercker, 2006). In such cases, Joseph and Linley (2005) argued that, while PTG (i.e., psychological wellbeing after a highly stressful event) may be associated over time with a subsequent increase of posttraumatic psychological adjustment (i.e., subjective well-being), the gradual decrease of psychological maladjustment does not necessarily contribute to PTG. In this way, discriminant validity is investigated by assessing whether the posttraumatic growth and posttraumatic psychological adjustment are two distinguish constructs. By performing an exploratory factor analysis with varimax rotation, we predicted that all the items of PTGI-SF would load in a single factor, while items of the measure that was used as an indicator of psychological adjustment (the Satisfaction with Life Scale, Diener, Emmons, Larsen, \& Griffin, 1985) would load in a different single factor, thus showing the empirical distinctiveness of these constructs.

\section{Method}

\section{Participants and Procedure}

The total sample of this study comprises 482 divorced adults (347 women; 72.0\%). Participants ranged from 24 to 65 years of age $(M=41.8$ years, $S D=8.2)$. Marriage duration was on average 11.1 years $(S D=7.8$ years; range: 1 month to 40 years), and the mean months since divorce were 62 ( $S D=62.04$ months). Participants were highly educated, with $74.2 \%$ having a university education $(M=$ 17.06 years of study, $S D=4.16$; range: 6 years to 30 years). Divorce was initiated by $54 \%$ of participants $(n=260)$. In consequence of the divorce process, $19 \%$ had received psychological or psychiatric treatment.

The online survey was available from June to November 2010 on a Portuguese internet research portal for divorce research. Participants were recruited through electronic divulgation (e.g., Portuguese universities mailing lists and notices on web forums) as well as announcements on national media. No compensation was offered to participants. Standard methodological and ethical guidelines for internet-based research were implemented to guarantee data quality (Birnbaum, 2007; Kraut et al., 2004; Reips, 2002).

\section{Measures}

\section{Posttraumatic Growth Inventory Short Form}

The Posttraumatic Growth Inventory Short Form is comprised by 10-items corresponding to the five dimensions of posttraumatic growth: relating to others, new possibilities, personal strength, spiritual change, and appreciation of life. 
Each dimension was assessed by two selected items from PTGI 21-item version. Instructions ask the subject to rate the degree to which each change occurred in their personal life as a result of the personal crisis. The response scale is a 6-point-Likert scale (from $0=I$ did not experience this change as a result of my crisis, to $5=I$ experienced this change to a very great degree as a result of my crisis). For the present study, instructions and Likert labels were adapted to divorced population. In the original version, scores on PTGI-SF range from 0 to 50, with higher scores reflecting a higher level of posttraumatic growth. Internal consistency values of the five original PTGI-SF scales, which contain two items each, ranged from .68 (Relating with others and Appreciation of Life factors) to .80 (Spiritual Change), in which the Cronbach $\alpha$ value of PTGI-SF total was .86. In the original article of the PTGI-SF validation, Cann et al. (2010) did not report mean and standard deviation values of the PTGI-SF total score. However, Kaler and colleagues (2011) reported a mean total score of the PTGI-SF of $20.40(S D=11.88)$ in their study with veterans from the Iraq war.

The Portuguese version of the PTGI-SF was developed using a backtranslation procedure by two independent translators. Discrepancies emerging from this process were discussed until they reached an agreement on a common version. The semantic equivalence between the items of the final version of the Portuguese PTGI-SF and the Portuguese version of the PTGI 21-item (Resende, Sendas, \& Maia, 2008) was verified and confirmed by a specialist in Portuguese semantics. Items of the Portuguese version of the PTGI-SF are presented in Table 1.

Table 1. Items of the Portuguese version of PTGI-SF (original items of the American version are in italics in parentheses)

Item 1 Alterei as minhas prioridades acerca do que é importante na vida (I changed my priorities about what is important in life).

Item 2 Tenho um maior apreço pelo valor da minha vida (I have a greater appreciation for the value of my own life).

Item 3 Sou capaz de fazer coisas melhores com a minha vida (I am able to do better things with my life).

Item 4 Compreendo melhor a espiritualidade (I have a better understanding of spiritual matters).

Item 5 Tenho um maior sentido de proximidade com os outros (I have a greater sense of closeness with others).

Item 6 Estabeleci um novo rumo para a minha vida (I established a new path for my life).

Item 7 Sei melhor que posso lidar com dificuldades (I know better that I can handle difficulties).

Item 8 Tenho uma fé religiosa mais forte (I have a stronger religious faith).

Item 9 Descobri que sou mais forte do que aquilo que pensava (I discovered that I'm stronger than I thought I was).

Item 10 Aprendi muito sobre como as pessoas são maravilhosas (I learned a great deal about how wonderful people are).

\section{Satisfaction with Life Scale}

The Satisfaction with Life Scale (SWLS; Diener et al., 1985) assesses personal global judgment of life satisfaction (e.g., "I am satisfied with my life"). The five-item SWLS was used as an indicator of psychological adjustment and subjective well-being (Chang, 1998). The items are answered on a 7-point Likert-scale. Higher scores reflect a higher subjective well-being. In the current sample, the internal consistency was .86 .

\section{Growth Motivation Index}

The Growth Motivation Index (GMI; Bauer et al., 2011) evaluates the motivation for personal growth, self-exploration, and self-improvement (Brown, Park, \& Folger, in press; Park, Bauer, \& Arbuckle, 2009). This 20 -item measure assesses experiential, cognitive, and extrinsic growth motivation. GMI includes items such as "I strive to improve my interpersonal relationships," "I try to create a work life (now or in the future) that is personally challenging and meaningful," and "I actively seek new perspectives on how to live my life, even if these new perspectives mean I've been wrong." Participants rated how often they put effort into growth and self-improvement in their daily life on a scale from 1 to 7 . Items were obtained from previous studies regarding narratives of growth goals, growth memories, and well-being (Bauer \& McAdams, 2004; Bauer et al., 2005). Higher scores in GMI represent higher levels of motivation for personal growth. The internal consistency for the total score in the current sample was .79.

\section{Data Analysis}

In order to assess construct validity, we first conducted a confirmatory factor analysis (CFA; AMOS 18.0) on the total sample with the purpose of testing the internal structure of PTGI-SF. The estimation method used was maximum likelihood. Multiple model fit indices were reported, including the chi-square statistic $\left(\chi^{2}\right)$, comparative fit index (CFI), the normed fit index (NFI), and the root-meansquare error of approximation (RMSEA) with its $90 \%$ confidence interval. Nonsignificant $\chi^{2}$ statistic, CFI, and NFI greater than .90 , and RMSEA less than .08 indicate good model fit. However, the $\chi^{2}$ statistic was not considered the major indicator of fit since it is affected by the size of the sample (Bollen \& Long, 1993; Hu \& Bentler, 1999; Kline, 2010).

Second, we examined the measurement invariance/equivalence of the final factor solution of the Portuguese PTGI-SF by multigroup CFA with maximum likelihood estimation with nested models. The assessment of the measurement invariance/equivalence of the factor model of the PTGI-SF based on divorce initiator status served to guarantee that items of the inventory operate homoge- 
neously across these two groups and measure posttraumatic growth in the same way in both groups. Three measurement invariance tests were conducted between divorce initiator status groups: factor-form invariance (i.e., configural invariance), metric invariance (i.e., factor loading), and factor covariance invariance (Chen, 2008; Raju, Laffitte, \& Byrne, 2002). The indicator used to test goodness of fit of measurement invariance models was $\Delta$ CFI (Chen, 2007; Cheung \& Rensvold, 2002). A CFI change of $\leq .01$ between a baseline model and the resulting model indicates measurement invariance (Cheung \& Rensvold, 2002; Glaesmer, Grande, Braehler, \& Roth, 2011).

Third, Cronbach's $\alpha$ coefficients were used to assess internal consistency of the final factor structure model of the PTGI-SF. Values between .60 to .70 indicate acceptable reliability, and a value of .70 or higher is treated as a good level of reliability (Nunnally \& Bernstein, 1994). Fourth, in order to examine convergent validity, we performed Pearson correlations between PTGI-SF total score and GMI. Finally, a factor analysis was conducted regarding PTG and satisfaction with life in order to assess divergent validity. The extraction method used was principal axis factoring with varimax rotation. A forced two-factor solution was performed, since two distinct constructs (posttraumatic growth and satisfaction with life) were expected (criterion for a significant factor loading > .30) (Straub, 1989). The Kaiser-Meyer-Olkin (KMO) measure of sampling adequacy was analyzed: A KMO of .50 or lower is considered barely acceptable, a value between .50-.70 is mediocre, between .70-.80 is good, between .80-.90 is great, and a KMO of $\geq .90$ is considered superb (Field, 2009).

\section{Results}

Associations between PTG and demographic variables were examined. Posttraumatic growth was negative correlated to age $(r=-.23, p<.001)$ and education $(r=-.16$, $p<.001)$. No relation was found between PTG and marriage duration $(r=-.06, n s)$ and time since divorce $(r=$ $-.04, n s)$. Women $(M=30.52, S D=11.21)$ reported higher levels of posttraumatic growth than men $(M=25.16, S D=$ $10.57), t(480)=4.79, p<.001)$. Finally, a significant difference was found between divorce initiators $(M=27.29$, $S D=11.51)$ and noninitiators $(M=30.25, S D=10.94)$, $t(480)=-2.82, p<.05)$.

In the Portuguese version, we tested the final oblique five-factor model proposed in the American version of the PTGI-SF. Goodness-of-fit indices demonstrated that this oblique five-factor model showed a very good fit to the data, $\chi^{2}(25)=104.68, p<.001, \mathrm{CFI}=.96, \mathrm{NFI}=.95$, and RMSEA $=.07(90 \% \mathrm{CI}=.06-.09)$. As presented in Figure 1 , standardized regression weights (factor loadings) ranged from .62 to .86 . The correlations between the five factors were all significant $(p<.001)$, ranging from .54 to .91 (Figure 1).

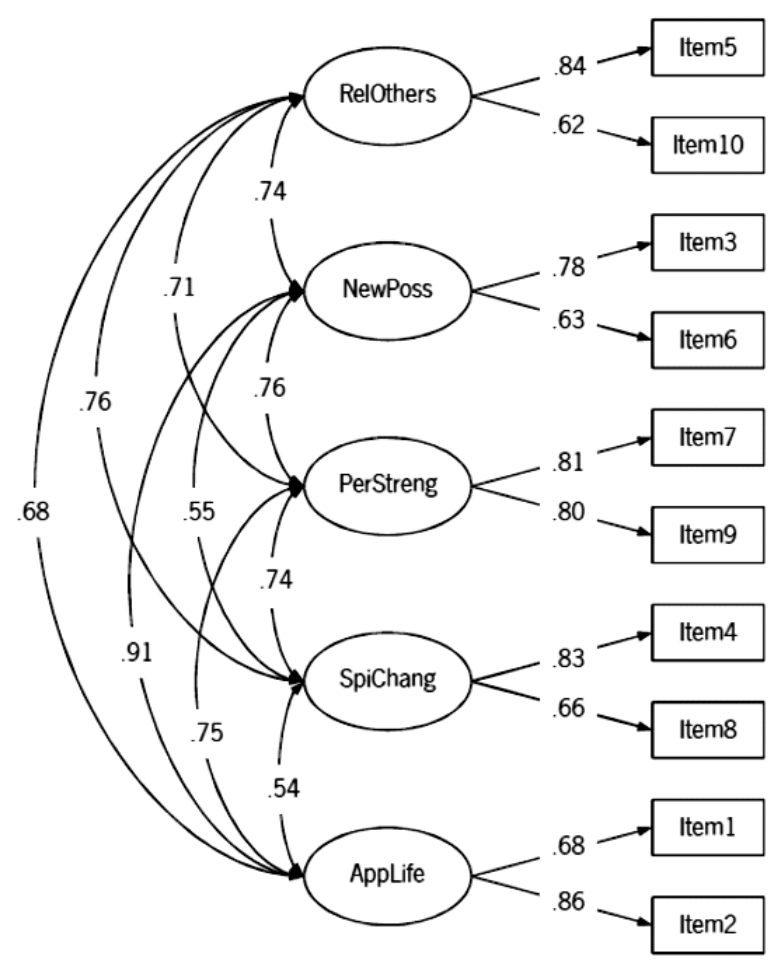

Figure 1. The oblique five-factor confirmatory model of the Portuguese version of the PTGI-SF. Curved, doubledheaded arrows express correlations between PTGI-SF factors. All correlations among PTGI-SF factors are significant at .001. The direction of the arrows indicates that participants' responses are influenced by the five latent constructs (factors). Standardized regression weights from the CFA are also presented. RelOthers = Relating to Others; NewPoss $=$ New Possibilities; PerStreng $=$ Personal Strength; SpiChang = Spiritual Change; AppLife $=$ Appreciation of Life.

One consequence of the high correlations among the five factors found in the postulated oblique factor model is that one can hypothesize that other possible factor models could fit the data more properly. More concretely, because of the high correlation between New Possibilities and Appreciation of Life (.91), these two factors in the five-factor solution may represent a single factor or can be accounted for by one common higher-order latent factor. Additionally, the high intercorrelations values indicated that all items may load on one factor or, in turn, the PTGI-SF items may load directly on the original five factors, and those factors may load on one higher-order factor. For that reason, we compared the original five-factor model with other four competing models via CFA in order to demonstrate the best underlying factor structure of the Portuguese version of PTGI-SF:

- Model A: the original oblique five-factor model proposed by PTGI-SF developers;

- Model B: an oblique four-factor solution, in which items of the New Possibilities and Appreciation of Life were 
Table 2. Fit indices of the five competing models

\begin{tabular}{lllllllll}
\hline Models & Description & $\chi^{2}$ & $d f$ & $\chi^{2} / d f$ & CFI & NFI & $\begin{array}{c}\text { RMSEA } \\
\text { RMSEA Confidence } \\
\text { interval (90\%) }\end{array}$ \\
\hline Model A & Oblique 5-factors (original model) & $104.68^{*}$ & 25 & 4.19 & .96 & .95 & .07 & $.06-.09$ \\
Model B & Oblique 4-factors & $114.28^{*}$ & 29 & 3.94 & .96 & .95 & .08 & $.06-.09$ \\
Model C & One second-order latent factor + 3 & $106.36^{*}$ & 27 & 3.94 & .96 & .95 & .08 & $.06-.09$ \\
& first-order latent factors & & & & & & & \\
Model D & One global second-order factor & $186.08^{*}$ & 30 & 6.20 & .92 & .91 & .10 & $.09-.12$ \\
Model E & One-factor & $334.93^{*}$ & 35 & 9.60 & .85 & .84 & .13 & $.12-.15$ \\
\hline
\end{tabular}

Note. ${ }^{*} p<.01$.

collapsed into a single factor, and the other three initial factors (Relating to Others, Personal Strength, and Spiritual Change) were maintained;

- Model C: a second-order latent factor plus three first-order latent factors oblique model, where factors of Relating to Others, Personal Strength, and Spiritual Change were conceptualized as intercorrelated first-order factors, and New Possibilities and Appreciation of Life, which in turn were understood as related but distinct first-order constructs where the degree of correlation between them would be explained by a common underlying higher-order factor;

- Model D: one global second-order latent factor, in which the higher-order factor could explain the correlation between the original five subscales that were understood as lower order factors;

- Model E: one-factor solution in which the posttraumatic growth was understood as a unitary construct.

Table 2 reports the fit indices for the five models. Fit indices revealed that Model D (one global second-order factor) and Model E (one-factor) poorly fit the data. Although the analyses also revealed a good fit for Model B and Model C, yielding .96, .95 and .08 for CFI, NFI, and RMSEA, respectively, Model A showed a residual better RMSEA fit (.07) than Model B or Model C. Although these three models exhibited a similar fit to the data, Model A (the original oblique five-factor model) was preferred as the factor solution of the Portuguese version of PTGI-SF for conceptual reasons (see Discussion below). Therefore, the consequent statistical analyses conducted to examine measurement invariance/equivalence, reliability, and convergent and divergent validities were based on the oblique five-factor model.

Multigroup CFA was conducted in order to compare measurement invariance/equivalence between the divorce initiators $(N=260)$ and divorce noninitiators $(N=$ 222) groups in the oblique five-factor model. The results of the sequence of gradually more restrictive tests of measurement invariance are reported in Table 3. Considering factor-form invariance, the tested model achieved an adequate fit, $\chi^{2}(50)=180.13, \mathrm{CFI}=.93, \mathrm{NFI}=.91$ and RMSEA $=.07$. Additionally, results showed that the invariance of factor loading (metric invariance) and factor covariance across the groups were supported $(\Delta \mathrm{CFI}=$
Table 4. Correlations among the five factors of the PTGISF for the two divorce initiative status groups

\begin{tabular}{llllll}
\hline & 1. & 2. & 3. & 4. & 5. \\
\hline 1. Relating to Others & - & .85 & .78 & .73 & .76 \\
2. New Possibilities & .68 & - & .83 & .64 & .93 \\
3. Personal Strength & .92 & .72 & - & .74 & .77 \\
4. Spiritual Change & .87 & .52 & .82 & - & .60 \\
5. Appreciation of Life & .59 & .81 & .68 & .52 & - \\
\hline
\end{tabular}

Notes. Factor correlations are above the diagonal for divorce initiators group and below the diagonal for divorce noninitiators group. All correlations among PTGI-SF factors for both groups were significant at $p<.001$.

$.00)$. Fit indices and factor loadings of PTGI-SF items across the two groups are presented in Table 3 . The correlations between the five factors ranged from .60 to .93 and from .52 to .92 for divorce initiators group and divorce noninitiators group, respectively (Table 4).

The mean of the PTGI-SF total score was $29.01(S D=$ 11.29; range: 0 to 50). The descriptive statistics of each scale were Relating to Others, $M=4.88(S D=2.91)$; New Possibilities, $M=7.35(S D=2.43)$; Personal Strength, $M=6.51$ $(S D=3.09)$; Spiritual Change, $M=3.53(S D=3.02)$; and Appreciation of Life, $M=6.75(S D=2.80)$. The internal consistency (assessed by Cronbach's $\alpha$ ) of the total score of PTGI-SF was .88. Although the scales' scores on the PTGISF have only two items each, the internal reliabilities were at good levels (Relating to others $=.70$; Personal Strength $=.79$; Spiritual Change = .71; Appreciation of Life = .74), with exception of the New Possibilities factor, which revealed an acceptable reliability $(\alpha=.66)$. Item-total correlations were very satisfactory for the total of the PTGI-SF, $r>.4$.

Concerning convergent validity, we evaluated the Pearson correlation between PTGI-SF and GMI. As expected, a moderate correlation between PTGI-SF and GMI was found $(r=.44, p<.001)$. Lastly, in order to examine the divergent validity of PTGI-items, a factor analysis on the PTGI-SF-items and SWLS-items confirmed two clear factors: Posttraumatic Growth (composed by all 10 items of the PTGI-SF) and Satisfaction with Life (composed by all five items of the SWLS). The value of the KMO was .87. There were no crossfactor loadings items (all $>.5$ ), demonstrating two distinctive constructs. No association was found between PTGI-SF and SWLS $(r=.04, n s)$. 


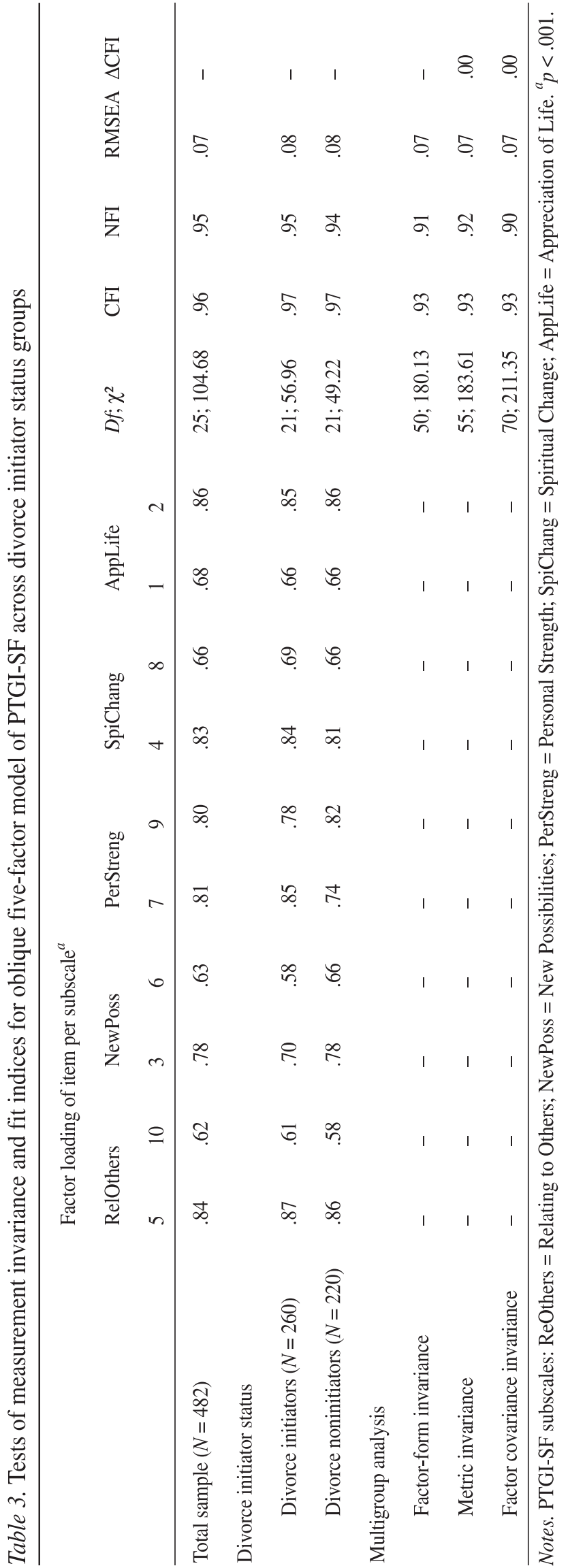

\section{Discussion}

Based on a sample of divorced adults, this study assessed the psychometric properties of the Portuguese version of the PTGI-SF. The inventory assesses five theoretically driven dimensions of positive psychological changes after stressful events. Our results confirm the factor structure, reliability, and convergent and discriminant validity of the Portuguese version of PTGI-SF. CFA identified a clear replication of the oblique five-factor structure of the PTGI-SF empirically tested by Cann et al. (2010) and Kaler et al. (2011).

As an analytic strategy we opted to initially test a fiveoblique factor model found by the PTGI-SF developers. Our results supported this proposed factor structure. However, in consideration of the high intercorrelations among the five factors, we compared the initial factor structure with four additional competing factor structures. The one-factor and one-higher-order latent factor models did not receive adequate fit to the data. These results were similar to those found by Kaler et al. (2011) and Taku et al. (2008), in which a single-factor solution presented the poorest fit to the data among the tested competing factor models of PTGI-SF and PTGI 21-item, respectively. By contrast, the original fiveoblique factor model, the four-oblique factor model, and the one-higher-order factor plus three first-order factor model received a good support for fitting the data. However, none of these three models showed an undoubted best fit to the data. In spite of this, the five-oblique factor model was ultimately selected as the final measurement solution of the Portuguese version of PTGI-SF for conceptual reasons. More concretely, compared with the other two models, the five-oblique factor solution best replicated the underlying factor structure that supports the theoretical formulations of PTG presented by the authors of the PTGI and the PTGI-SF (Cann et al., 2010; Tedeschi \& Calhoun, 1996). According to the PTGI developers, the original five factors of the PTGI assess three broad categories of posttraumatic growth: changes in perceptions of the self, a changed sense in the relationships with others, and a perceived change in the philosophy of life (Tedeschi \& Calhoun, 1996). Previous theoretical and empirical work suggested that items of New Possibilities original dimension are indicators of the PTG category of perceived changes in the self, whereas items of Appreciation with Life are strictly associated with the category of perceived changes in the philosophy of life (Calhoun \& Tedeschi, 2006, Palmer, Graca, \& Occhietti, 2012; Weiss \& Berger, 2006). Despite the fact that Models B and C are more parsimonious factor solutions than Model A, they statistically suggest a comprising into a single factor (Model B) or an underlying higher-order factor (Model C) items that are originally developed to assess two distinct categories of PTG. Conceptually, New Possibilities dimension describes the self-perception of one's own personal potential and opportunities of self-development, whereas Appreciation with Life dimension entails the perception of a new meaning in life and new life priorities (Calhoun \& Tedeschi, 
2006). Although the authors emphasized that the three categories are intercorrelated, each category measures a different type of stress-related growth (Calhoun \& Tedeschi, 2006). Therefore, Models B and C are theoretically less consistent with PTG construct, when compared with Model A, which replicates the factorial structure of PTG highlighted by the authors and supported empirically by other studies (e.g., Jaarsma, Pool, Sanderman, \& Ranchor, 2006; Kaler et al., 2011; Taku et al., 2008).

The multigroup CFA showed evidence for the measurement invariance (factor structure, factor loading, and factor covariances) of PGTI-SF across divorce initiators and noninitiators groups. Our results revealed that posttraumatic growth is measured in the same way across these groups when the five-oblique factor model of the Portuguese version of the PTGI-SF is used. This result assumes particular relevance for the reason that the divorce initiator status was selected to test factor structure invariance due to the potential capability of this in distinguishing the more likely stressed individuals from the less likely stressed divorced adults. Our results showed the possibility of producing explainable and meaningful comparisons across the groups based on divorce initiator status, which is empirically considered as a significant variable in the study of the posttraumatic growth construct in samples with divorced adults. No previous published studies testing the invariance of the PTGI-SF were known, and only a single study tested and confirmed the measurement equivalence of the PTGI 21-item (Brunet et al., 2010). In consequence, our research presents a methodological innovation in the study of psychometric properties of the PTGISF. Our multigroup CFA results suggest that differences in PTG between the compared groups reproduce true group differences and are not contaminated by group-specific characteristics nonrelated to PTG (Gregorich, 2006). With samples of divorced adults, future research could still evaluate the PTGI-SF invariance across other groups, namely, those that show mean score differences in perceived stress with divorce experience, current intimate relationship status, and social support levels. As noted by Brunet et al. (2010), the confirmation of the factor model invariance across different groups may support the identification of which individuals experience less growth and consequently allow the researchers to understand more accurately the moderate mechanisms of PTG.

Concerning reliability, results revealed that the internal consistency coefficients of the five factors and of the total score of the PTGI-SF were from adequate to good, being comparable to those obtained in Cann et al. (2010) and Kaler et al. (2011). Finally, convergent and discriminant validity were also demonstrated. Just as expected, a moderate correlation between PTGI-SF and GMI was found. This result showed that perceived changes in the self, in the relations with others and in the philosophy of life after a stressor are associated to the personal motivation to self-improvement, self-exploration, and personal psychological growth. Our results are similar to those obtained in other studies that previously examined the association between
PTG and other psychological well-being indicators (Durkin \& Joseph, 2009; Taubman-Ben-Ari et al., in press; Triplett, Tedeschi, Cann, Calhoun, \& Reeve, in press). These associations were found in studies with a wide diversity of stressors. More concretely, Taubman-Ben-Ari et al. (in press) found a positive relationship between personal growth assessed by PTGI after first-child birth and mothers' meaning and purpose in life, while similar results were also obtained in a sample of cancer survivors (Park, Edmondson, Fenster, \& Blank, 2008).

Regarding discriminant validity, items of the PTGI-SF and SWLS loaded on two different factors, as expected. Additional analysis also showed no significant association between PTG and satisfaction with life. These findings suggest that PTG and psychological adjustment are distinct constructs. Our results are in line with conceptual frameworks that propose theoretical differentiation between (posttraumatic) psychological growth and (posttraumatic) psychological adjustment (Joseph \& Linley, 2005; Keyes et al., 2002; Staudinger \& Kunzmann, 2005; Tedeschi et al., 2007) - and they suggest that psychological growth after divorce is different from the levels of psychological adjustment to divorce, but that they may co-occur with psychological adjustment to divorce. The nonsignificant association between PTG and satisfaction with life as an indicator of global psychological adjustment found in our study is also corroborated by previous empirical and metaanalytic studies (Cordova, Cunningham, Carlson, \& Andrykowski, 2001; Helgeson et al., 2006).

The current research offers a psychometric valid and reliable version of the Portuguese PTGI-SF which should be read with some precaution. First, the current sample was composed of highly educated adults rather than an accurately representative sample. Second, these results are circumscribed to a specific stressful life event; further research should also consider other highly stressful life events. In this sense, future research should test a generalization of these results, using samples that represent wider sociodemographic characteristics and a variety of populations as well. Finally, as in other studies of international versions of the PTGI (Jaarsma et al., 2006), we did not assess the perceived impact of divorce experience in our sample. This methodological option is based on the recent conceptual views of psychological growth, in which stressrelated growth measures can be administered to assess individual's perception of personal changes in the self, interpersonal relationships, and life philosophy in a wide diversity of life events (Krumrei et al., 2009; Sawyer \& Ayers, 2009; Staudinger \& Kunzmann, 2005; Taku et al., 2008; Tedeschi et al., 2007). On the other hand, the assessment of perceived negative impact of divorce could have been relevant since, according to Tedeschi and Calhoun (1996), the comparison of the PTGI scores between highly stressed individuals and nonhighly stressed individuals may be an additional tool to verify PTG construct validity, by predicting that highly stressed individuals would be more likely to report higher levels of PTG (Tedeschi \& Calhoun, 1996). 
We attenuated this potential limitation by examining the differences in PTGI-SF mean scores between divorce initiators and divorce noninitiators. Considering that this demographic variable is one of the best at distinguishing between more likely stressed individuals from less likely stressed individuals, our results showed that the group with more likely stress (noninitiators) also reported higher levels of posttraumatic growth, in accordance with Tedeschi and Calhoun's (1996) conceptual predictions. Additionally, the PTGI-SF mean score and standard deviation in our sample of divorced adults were very similar to those obtained by Kaler et al. (2011), who administered the PTGI-SF to a sample that had experienced a life-threatening event (Iraq war veterans), indicating that the current Portuguese version of the PTGI-SF assessed stress-related growth in a comparable way to the American version of the instrument.

Nevertheless, considering psychometric properties of the American and Portuguese versions of PTGI-SF, no significant cultural differences are presented that could require alternative content to be assessed as part of PTG, as suggested by Cann et al. (2010). The present study confirmed that the Portuguese translation of PTGI-SF is an adequate and valid instrument to measure PTG after personal crises.

\section{Acknowledgments}

This study was supported by the Portuguese Foundation of Science and Technology through a $\mathrm{PhD}$ fellowship to the first author (SFRH/BD/43525/2008).

\section{References}

Amato, P. (2000). The consequences of divorce for adults and children. Journal of Marriage and Family, 62, 1269-1287.

American Psychiatric Association. (2000). Diagnostic and statistical manual of mental disorders (4th ed., text revision). Washington, DC: American Psychiatric Association.

Bauer, J., \& McAdams, D. (2004). Growth goals, maturity, and well-being. Developmental Psychology, 40, 114-127.

Bauer, J., McAdams, D., \& Sakaeda, A. (2005). Interpreting the good life: Growth memories in the lives of mature, happy people. Journal of Personality and Social Psychology, 88(1), 203-217.

Bauer, J., Park, S., Wayment, H., Lauer, A., Perciful, M., Arbuckle, N., \& Laffitte, L. (2011). Growth motivation for two paths of personality development. Manuscript submitted.

Birnbaum, M. (2007). Designing internet-based experiments. In U.-D. Reips (Ed.), The Oxford handbook of internet psychology (pp. 391-404). New York: Oxford University Press.

Bollen, K., \& Long, S. (1993). Testing structural equation models. Thousand Oaks, CA: Sage.

Breslau, N., \& Kessler, R. (2001). The stressor criterion in DSMIV posttraumatic stress disorder: An empirical investigation. Biological Psychiatry, 50, 699-704.
Brewin, C., Lanius, R., Novac, A., Schnyder, U., \& Galea, S. (2009). Reformulating PTSD for DSM-V: Life after criterion A. Journal of Traumatic Stress, 22, 366-373.

Brown, C., Park, S., \& Folger, S. (in press). Growth motivation as a moderator of behavioral self-handicapping in women. The Journal of Social Psychology.

Brunet, J., McDonough, M., Hadd, V., Crocker, P., \& Sabiston, C. (2010). The Posttraumatic Growth Inventory: An examination of the factor structure and invariance among breast cancer survivors. Psycho-Oncology, 19, 830-838.

Calhoun, L.G., \& Tedeschi, R.G. (2006). The foundations of posttraumatic growth: An expanded framework. In L. G. Calhoun \& R.G. Tedeschi (Eds.), Handbook of posttraumatic growth: Research and practice (pp. 3-23). Mahwah, NJ: Erlbaum.

Cann, A., Calhoun, L., Tedeschi, R., Taku, K., Vishnevsky, T., Triplett, K., \& Danhauer, S. (2010). A short form of the Posttraumatic Growth Inventory. Anxiety, Stress, and Coping, 23, 127-137.

Chang, E. (1998). Dispositional optimism and primary and secondary appraisal of a stressor: Controlling for confounding influences and relations to coping and psychological and physical adjustment. Journal of Personality and Social Psychology, $74,1109-1120$.

Chen, F. (2007). Sensitivity of goodness of fit indexes to lack of measurement invariance. Structural Equation Modeling, 14, 464-504.

Chen, F. (2008). What happens if we compare chopsticks with forks? The impact of making inappropriate comparisons in cross-cultural research. Journal of Personality and Social Psychology, 95, 1005-1018.

Cheung, G., \& Rensvold, R. (2002). Evaluating goodness-of-fit indexes for testing measurement invariance. Structural Equation Modeling, 9, 233-255.

Cordova, M., Cunningham, L., Carlson, C., \& Andrykowski, M. (2001). Posttraumatic growth following breast cancer: A controlled comparison study. Health Psychology, 20, 176-185.

Davis, D., Shaver, P., \& Vernon, M. (2003). Physical, emotional, and behavioral reactions to breaking up: The roles of gender, age, emotional involvement, and attachment style. Personality and Social Psychology Bulletin, 29, 871-884.

Diener, E., Emmons, R., Larsen, R., \& Griffin, S. (1985). The Satisfaction with Life Scale. Journal of Personality Assessment, 49, 71-75.

Dohrenwend, B. (2010). Toward a typology of high-risk major stressful events and situations in posttraumatic stress disorder and related psychopathology. Psychological Injury and Law, 3, 89-99.

Durkin, J., \& Joseph, S. (2009). Growth following adversity and its relation with subjective well-being and psychological wellbeing. Journal of Loss and Trauma, 14, 228-234.

Engelkemeyer, S., \& Marwit, S. (2008). Posttraumatic growth in bereaved parents. Journal of Traumatic Stress, 21, 344-346.

Field, A. (2009). Discovering statistics using SPSS (3rd ed.). London: Sage.

Frazier, P., \& Cook, S. (1993). Correlates of distress following heterosexual relationship dissolution. Journal of Social and Personal Relationships, 10(1), 55-67.

Frazier, P., \& Kaler, M. (2006). Assessing the validity of self-reported stress-related growth. Journal of Consulting and Clinical Psychology, 74, 859-869. 
Glaesmer, H., Grande, G., Braehler, E., \& Roth, M. (2011). The German version of the Satisfaction with Life Scale (SWLS): Psychometric properties, validity, and population-based norms. European Journal of Psychological Assessment, 27, 127-132.

Gregorich, S.E. (2006). Do self-report instruments allow meaningful comparisons across diverse population groups? Testing measurement invariance using the confirmatory factor analysis framework. Medical Care, 44(11 Suppl. 3), S78-S94.

Helgeson, V., Reynolds, K., \& Tomich, P. (2006). A meta-analytic review of benefit finding and growth. Journal of Consulting and Clinical Psychology, 74, 797-816.

Holmes, T., \& Rahe, R. (1967). The Social Readjustment Rating Scale. Journal of Psychosomatic Research, 11, 213-218.

Hu, L., \& Bentler, P. (1999). Cutoff criteria for fit indexes in covariance structure analysis: Conventional criteria versus new alternatives. Structural Equation Modeling, 6, 1-55.

Jaarsma, T. A., Pool, G., Sanderman, R., \& Ranchor, A. (2006). Psychometric properties of the Dutch version of the posttraumatic growth inventory among cancer patients. Psycho-Oncology, 15, 911-920.

Joseph, S., \& Linley, A. (2005). Positive adjustment to threatening events: An organismic valuing theory of growth through adversity. Review of General Psychology, 9, 262-280.

Kaler, M., Erbes, C., Tedeschi, R., Arbisi, P., \& Polusny, M. (2011). Factor structure and concurrent validity of the Posttraumatic Growth Inventory-Short Form among veterans from the Iraq War. Journal of Traumatic Stress, 24, 200-207.

Keyes, C., Shmotkin, D., \& Ryff, C. (2002). Optimizing well-being: The empirical encounter of two traditions. Journal of Personality and Social Psychology, 82, 1007-1022.

King, L., \& Raspin, C. (2004). Lost and found possible selves, subjective well-being, and ego development in divorced women. Journal of Personality, 72, 603-632.

Kline, R. (2010). Principles and practice of structural equation modeling. New York: Guilford.

Kraut, R., Olson, J., Banaji, M., Bruckman, A., Cohen, J., \& Couper, M. (2004). Psychological research online: Report of Board of Scientific Affairs' Advisory Group on the conduct of research on the internet. The American Psychologist, 59, 105-117.

Krumrei, E., Mahoney, A., \& Pargament, K. (2009). Divorce and the divine: The role of spirituality in adjustment to divorce. Journal of Marriage and Family, 71, 373-383.

Kulik, L., \& Heine-Cohen, E. (2011). Coping resources, perceived stress and adjustment to divorce among Israeli women: Assessing effects. The Journal of Social Psychology, 151, 5-30.

Lamela, D., Figueiredo, B., \& Bastos, A. (2010). Adaptação ao divórcio e relações coparentais: Contributos da teoria da vinculação [Adjustment to divorce and co-parental relations: Contributions from the theory of attachment]. Psicologia: Reflexão e Crítica, 23, 562-574.

Linley, P., \& Joseph, S. (2004). Positive change following trauma and adversity: A review. Journal of Traumatic Stress, 17(1), 11-21.

McCann, L., \& Pearlman, L. (1990). Psychological trauma and the adult survivor: Theory, therapy, and transformation. New York: Brunner-Routledge.

Middeldorp, C., Cath, D., Beem, A., Willemsen, G., \& Boomsma, D. (2008). Life events, anxious depression and personality: A prospective and genetic study. Psychological Medicine, 38, 1557-1565.

Miller, G., Chen, E., \& Zhou, E. (2007). If it goes up, must it come down? Chronic stress and the hypothalamic-pituitary-adrenocortical axis in humans. Psychological Bulletin, 133(1), 25-45.

Mol, S., Arntz, A., Metsemakers, J., Dinant, G., Vilters-van Montfort, P., \& Knottnerus, J. (2005). Symptoms of posttraumatic stress disorder after nontraumatic events: Evidence from an open population study. The British Journal of Psychiatry, 186, 494-499.

Nunnally, J., \& Bernstein, I. (1994). Psychometric theory. New York: McGraw-Hill.

Palmer, G., Graca, J., \& Occhietti, K. (2012). Confirmatory factor analysis of the Posttraumatic Growth Inventory in a veteran sample with posttraumatic stress disorder. Journal of Loss and Trauma, 17, 545-556.

Park, C., Edmondson, D., Fenster, J., \& Blank, T. (2008). Meaning making and psychological adjustment following cancer: The mediating roles of growth, life meaning, and restored justworld beliefs. Journal of Consulting and Clinical Psychology, 76, 863-875.

Park, S., Bauer, J., \& Arbuckle, N. (2009). Growth motivation attenuates the self-serving attribution. Journal of Research in Personality, 43, 914-917.

Powell, S., Rosner, R., Butollo, W., Tedeschi, R. G., \& Calhoun, L. G. (2003). Posttraumatic growth after war: A study with former refugees and displaced people in Sarajevo. Journal of Clinical Psychology, 59(1), 71-83.

Raju, N., Laffitte, L., \& Byrne, B. (2002). Measurement equivalence: A comparison of methods based on confirmatory factor analysis and item response theory. Journal of Applied Psychology, 87, 517-529.

Reips, U.-D. (2002). Standards for internet-based experimenting. Experimental Psychology, 49, 243-256.

Resende, C., Sendas, S., \& Maia, Â. (2008). Estudo das características psicométricas do Posttraumatic Growth Inventory PTGI - (Inventário de Crescimento Pós-Traumático) para a população portuguesa [Study of the psychometric properties of the Posttraumatic Growth Inventory for the Portuguese population]. In A. Noronha, C. Machado, L. Almeida, M. Gonçalves, S. Martins, \& V. Ramalho (Eds.), XIII Conferência Internacional de Avaliação psicológica: Formas e contextos (pp. 1-16). Braga, Portugal: Psiquilibrios Edições.

Robinson, J., \& Larson, C. (2010). Are traumatic events necessary to elicit symptoms of posttraumatic stress?. Psychological Trauma: Theory, Research, Practice, and Policy, 2(2), 71.

Ryan, R., \& Deci, E. (2001). On happiness and human potentials: A review of research on hedonic and eudaimonic well-being. Annual Review of Psychology, 52, 141-166.

Sakraida, T. (2005). Divorce transition differences of midlife women. Issues in Mental Health Nursing, 26, 225-249.

Sawyer, A., \& Ayers, S. (2009). Posttraumatic growth in women after childbirth. Psychology and Health, 24, 457-471.

Staudinger, U. M., \& Kunzmann, U. (2005). Positive adult personality development. European Psychologist, 10, 320-329.

Straub, D. (1989). Validating instruments in MIS research. MIS Quarterly, 13, 147-166.

Taku, K., Cann, A., Calhoun, L., \& Tedeschi, R. (2008). The factor structure of the posttraumatic growth inventory: A comparison of five models using confirmatory factor analysis. Journal of Traumatic Stress, 21, 158-164. 
Tashiro, T., \& Frazier, P. (2003). "I'll never be in a relationship like that again": Personal growth following romantic relationship breakups. Personal Relationships, 10(1), 113-128.

Tashiro, T., Frazier, P., \& Berman, M. (2006). Stress-related growth following divorce and relationship dissolution. In M. Fine \& J. Harvey (Eds.), Handbook of divorce and relationship dissolution (pp. 361-384). Mahwah, NH: Erlbaum.

Taubman-Ben-Ari, O., Ben Shlomo, S., \& Findler, L. (in press). Personal growth and meaning in life among first-time mothers and grandmothers. Journal of Happiness Studies.

Tedeschi, R., \& Calhoun, L. (1996). The Posttraumatic Growth Inventory: Measuring the positive legacy of trauma. Journal of Traumatic Stress, 9, 455-471.

Tedeschi, R., \& Calhoun, L. (2004). Posttraumatic growth: Conceptual foundations and empirical evidence. Psychological Inquiry, 15(1), 1-18.

Tedeschi, R., Calhoun, L., \& Cann, A. (2007). Evaluating resource gain: Understanding and misunderstanding posttraumatic growth. Applied Psychology, 56, 396-406.

Thomas, C., \& Ryan, M. (2008). Women's perception of the divorce experience: A qualitative study. Journal of Divorce and Remarriage, 49, 210-224.

Tran, V., Wiebe, D., Fortenberry, K., Butler, J., \& Berg, C. (2011). Benefit finding, affective reactions to diabetes stress, and diabetes management among early adolescents. Health Psychology, 30, 212-219.

Triplett, K., Tedeschi, R., Cann, A., Calhoun, L., \& Reeve, C. (in press). Posttraumatic growth, meaning in life, and life satisfaction in response to trauma. Psychological Trauma: Theory, Research, Practice, and Policy.

Vaughan, M., \& Waehler, C. (2010). Coming out growth: Conceptualizing and measuring stress-related growth associated with coming out to others as a sexual minority. Journal of Adult Development, 17, 94-109.

Wallerstein, J. (1986). Women after divorce: Preliminary report from a ten-year follow-up. American Journal of Orthopsychiatry, 56(1), 65-77.

Wang, H., \& Amato, P. (2000). Predictors of divorce adjustment: Stressors, resources, and definitions. Journal of Marriage and Family, 62, 655-668.

Weathers, F., \& Keane, T. (2007). The criterion A problem revisited: Controversies and challenges in defining and measuring psychological trauma. Journal of Traumatic Stress, 20, 107-21.

Weinrib, A., Rothrock, N., Johnsen, E., \& Lutgendorf, S. (2006). The assessment and validity of stress-related growth in a community-based sample. Journal of Consulting and Clinical Psychology, 74, 851-858.

Weiss, T., \& Berger, R. (2006). Reliability and validity of a Spanish version of the Posttraumatic Growth Inventory. Research on Social Work Practice, 16, 191-199.

Zoellner, T., \& Maercker, A. (2006). Posttraumatic growth in clinical psychology: A critical review and introduction of a two component model. Clinical Psychology Review, 26, 626-653.

Published online: January 20, 2013

Diogo Lamela

School of Psychology

University of Minho

Campus de Gualtar

4710-057 Braga

Portugal

Tel. +351253604220

Fax +351253604224

E-maildlamela@ese.ipvc.pt 